\title{
Leibniz's Lost Argument Against Causal Interaction
}

\author{
TOBIAS FLATTERY \\ Wake Forest University
}

\begin{abstract}
Leibniz accepts causal independence, the claim that no created substance can causally interact with any other. And Leibniz needs causal independence to be true, since his wellknown pre-established harmony is premised upon it. So, what is Leibniz's argument for causal independence? Sometimes he claims that causal interaction between substances is superfluous; sometimes he claims that it would require the transfer of accidents, and that this is impossible. But when Leibniz finds himself under sustained pressure to defend causal independence, those are not the reasons that he marshals in its defense. Instead, deep into his long correspondence with Burchard de Volder, he gives a different sort of argument, one that has gone nearly unnoticed by commentators and has not yet been properly understood. In part, this is because the argument develops slowly over four years of correspondence. It emerges in early 1704, but it is formulated tersely and appears murky unless understood in light of Leibniz and De Volder's tangled exchanges. There Leibniz argues that, on his distinctive ontology of an infinity of created substances, no two created substances could possibly causally interact, for roughly the same reasons that some Cartesians like De Volder deny interaction between minds and bodies on their substance dualist ontology. In this paper I draw out this lost argument, explain it and the metaphysics on which Leibniz builds it, and untangle Leibniz and De Volder's exchanges concerning causation from which this argument results.
\end{abstract}

\section{Introduction}

The created world appears to us as a place full of pushings and pullings, givings and receivings - a place populated by things that act, react, and interact with one another. On Leibniz's view, only part of this appearance is veridical: the created world, he thinks, is indeed populated by substances that act and react. ${ }^{1}$ In

1. Even though Leibniz thinks of God as a substance-though certainly a special one-for the sake of convenience I'll use the term 'substance' to mean 'created substance', unless stated otherwise. 
fact, on his view, activity is essential to the nature of substance. He writes that "substances . . cannot be conceived in their bare essence without activity, and that activity is of the essence of substance in general" (A 6.6.65/AG 304; cf. G IV 509/AG 159). Thus Leibniz accepts what I shall call Causal Activity: every created substance is capable of acting. ${ }^{2}$

While the idea that the appearance of activity is veridical is historically commonplace, Leibniz also thinks that, despite their genuine activity and the appearance of interactivity, no substance in fact interacts with any other. "Speaking with metaphysical rigor," he says, "there is no real influence of one created substance on another" (G IV 484-485/AG 143; cf. C 521/AG 33; G VI 607-608/ AG 213-214; LDV 319). Moreover, he thinks, no two substances could causally interact: "what are truly called substances ... have no influence on one another .... I think that the doctrine is necessary" (LDV 275). Thus Leibniz accepts what I shall call Causal Independence: necessarily, for any two created substances, the first cannot cause changes in the second.

What, then, do substances' actions produce, if not changes in one another? Changes in themselves: "because modifications vary, and whatever is the source of variations is truly active, it must therefore be said that simple substances ... produce in themselves a certain series of internal variations" (C 14/MP 175; cf. G VI 598/AG 207; G III 657). ${ }^{3}$ So, each substance is capable of producing changes of its own accidents or modifications. 4,5

Although the question why Leibniz accepts Causal Activity is interestingand I address this question in $\$ 2$ below - my primary concern here is the question why he accepts Causal Independence. What is his argument for Causal Independence? He needs one, not least because this thesis bears a great deal of philosophical weight in his metaphysics. For instance, Causal Independence provides 160).

2. Leibniz also thinks that something is active if and only if it is a substance (G IV 509/AG

3. Many commentators agree that Leibnizian created substances are genuine efficient causes. See, e.g., Mates (1986: 206), Adams (1994: 97), Jolley (1998: 605), Bennett (2001: 242, 270), Carlin (2006: 231ff.), McDonough (2007; 2008), and Jorati (2015). A few commentators deny this. For instance, on Lee's reading, a created substance is causally efficacious only in the attenuated sense that "it provides the reasons that determine and demand God's productive actions" (2004: 225), and thus God is the sole productive cause. For rebuttal, see McDonough (2007). Sleigh (2009: 270) also suggests that created monads are not efficient causes, but doesn't develop the interpretation at length.

4. I'll use the terms 'accident' and 'modification' interchangeably. Leibniz frequently does so, too, also with the terms 'mode', 'quality', and 'state'. See, e.g., LDV 277; T \$396/G VI 352; A 6.6.379/ NE 379 .

5. God is involved, too, of course. Leibniz agrees with the view that only God creates ex nihilo, but allows that each created substance can produce effects in an already existing created substance (though on Leibniz's view, only in itself). See T \$395/G VI 350-351. For discussion of Leibniz on the relation between God's creative activity and creaturely causal activity, see McDonough (2007). For Scholastic context, see Freddoso (1994). 
part of the crucial motivation to accept his pre-established harmony. According to his pre-established harmony things in the world appear to correspond one with another, and in fact do; but what explains this correspondence is not any direct interaction between distinct substances, but rather each substance's own individual, internal nature. ${ }^{6}$ By a stream of immanent, self-contained activity, each substance continually produces its own changes in accordance with a sort of script built into its nature. ${ }^{7}$ God's choice to create a particular set of these substances ensures that what happens to each is in perfect harmony with what happens to every other (G IV 485/AG 143; G IV 498-500/AG 147-149).

But the success of Leibniz's pre-established harmony turns on the truth of the two claims above concerning the metaphysics of causation, namely, Causal Activity and Causal Independence. Leibniz's general argument for pre-established harmony proceeds by way of ruling out its major competitors, namely, interactionism and occasionalism, each of which accepts one but rejects the other of the two claims above. According to occasionalism, Causal Independence is true but Causal Activity is false. Leibniz rejects occasionalism in part because he sides with interactionists in accepting Causal Activity. ${ }^{8}$ According to the other competitor, interactionism, Causal Activity is true but Causal Independence is false. Leibniz sides with occasionalists in accepting Causal Independence, so he cannot accept interactionism (G IV 498-500/AG 147-149). Thus, for one who already accepts Causal Activity, Causal Independence motivates pre-established harmony by ruling out the other alternative (viz., interactionism). However, since things in the world certainly appear to interact, it is prima facie plausible that things really do interact. 9 So there is good reason to reject Causal Independence at the outset, and thus good reason to accept interactionism over pre-established harmony-unless there is a countervailing reason to accept Causal Independence. Thus, given the philosophical weight that Causal Independence bears, the need for a good argument to support it is clear. So, again, why does Leibniz accept Causal Independence?

In various texts Leibniz gives reasons for Causal Independence, though usually these are given quickly or in passing comments, in part because he is not

6. Note that Causal Independence is not the same thesis as the pre-established harmony. One can accept the former without accepting the latter (as occasionalists do), but not vice versa.

7. I borrow the script metaphor from Woolhouse (1982).

8. Leibniz rejects occasionalism for at least two other reasons: occasionalists posit God's performing perpetual miracles (G VI 595-596/AG 197; cf. G IV 484/AG 143), which is not fitting for a perfect God; and they appeal to God as the only cause, which is a philosophically dubious, "deus ex machina" move (G IV 499/AG 148).

9. Leibniz himself admits that, according to the "common opinion", interactionism is true (G IV 484/AG 143; G IV 440/AG 47). 
usually under much pressure to defend this thesis. ${ }^{10}$ For the most part, Leibniz's reasons in all of these texts boil down to one of the following two. ${ }^{11}$ First, sometimes he claims that inter-substantial causal interaction is superfluous. Given that each substance, in his view, already has the wherewithal to bring about all that happens to itself, there is no need to posit any cross-substance causal interaction. ${ }^{12}$ Second, and more often, Leibniz claims (or at least hints) that such interaction would require the transfer of substances' accidents, and that accident transfer is in general impossible. ${ }^{13}$ (I discuss this anti-transfer argument briefly in $\S 2.2$ below.)

However, when Leibniz does find himself under sustained pressure to defend Causal Independence-deep into his long correspondence with Burchard de Volder-he does not ultimately rely on those reasons. Instead, he gives a different, new sort of argument, one that has gone nearly unnoticed by commentators and has not yet been properly understood. ${ }^{14}$ In part this is because the argument slowly develops over the course of four years of correspondence with, and under sustained dialectical pressure from, De Volder. The argument appears in early 1704 but is formulated tersely and appears murky unless understood in light of the two correspondents' tangled exchanges over the years. There Leibniz argues that, on his distinctive ontology of an infinity of substances, no two substances could possibly causally interact, for roughly the same reasons that some Cartesians like De Volder deny interaction between minds and bodies on their substance dualist ontology. Although components of this new argument-for instance, that every substance has a unique nature (see $\$ 3$ below)-are claims that Leibniz had already made in earlier texts, and although his acceptance of Causal Independence played a central role in previous texts engaging a largely

10. Leibniz would have expected that many in his intended audience were occasionalists who already rejected causal interaction between created substances, or were at least unsympathetic to what was widely understood as an accident transference model of causal interaction held by many Scholastics. See Radner (1985: 47, 45-46); cf. Clatterbaugh (1999: 143).

11. For brief discussions of these reasons for denying interactionism, see O'Neill (1993), Clatterbaugh (1999: 142-143), Lee (2018: 108), and Jorati (2017: 41-43). Cf. Loeb (1981: 269ff.).

12. Leibniz offers or suggests this 'no need' style of argument at C 521/AG 33; G II 47/LA 51; G II 69-71/LA 84-87; G IV 484/AG 144; and G VII 312/MP 79.

13. Leibniz suggests this 'no accident transfer' style of argument at G IV 484/AG 143-144; G IV 495/WF 49; G IV 497-499/AG 147-148; G IV 501; G IV 520/WF 82; the exchanges in LDV 157, 169, 181, 279, 319; G VI 607-608/AG 213-214; C 521/AG 33; G IV 451/AG 58; G IV 148/L 126; G IV 554/L 574; G VII 312/MP 79; A 6.6.224/NE 224; A 6.6.379/NE 379. In some texts Leibniz seems to express this anti-transfer argument as a disjunction: causal interaction must happen via the transfer of either accidents or material parts, neither of which is possible. See G VI 607-608/AG 213-214 and G IV 498-499/L 460 .

14. Loeb (1981: 294ff.), Sleigh (1990: 166), and Bennett (2001: 240-242) have briefly discussed the text in which this argument is found, though, as I explain more in the sections that follow, they misunderstand it-an understandable misunderstanding, given how tangled the Leibniz-De Volder correspondence is. 
Cartesian audience-for instance, the New System of Nature and his subsequent replies to critics - in none of those texts did Leibniz use those claims to build (or even suggest) an argument like the one he gives to De Volder in 1704. In the sections that follow, I draw out this lost argument, explain it and the metaphysics on which Leibniz builds it, and untangle Leibniz and De Volder's exchanges concerning causation from which this argument results.

\section{De Volder, Causal Activity, and Causal Independence}

In a letter to De Volder written on January 21, 1704, a frustrated Leibniz offers the following compressed defense of Causal Independence:

You say, Nothing prevents 'substances of the same nature' from acting on one another. But you know that philosophers have, in fact, denied action between similar things. And what prevents substances of different natures from acting on one another? When you have explained that, you will see that it prevents all finite substances from influencing one another. Not to mention the fact that all substances are of different natures, and that there are no two things in nature that differ in number alone. (LDV 291, italics added)

Clearly Leibniz is responding to De Volder's claims from a prior letter and means to persuade him that no finite substances can causally interact. But Leibniz's reasoning here is hardly perspicuous - at least not taking the paragraph in isolation, a paragraph that Robert Sleigh has with justification called "gallingly enigmatic" (1990: 166). Properly understood, however, Leibniz's argument is no puzzle, though it is not one of his usual arguments. Making sense of the argument requires understanding how it grows out of threads of their conversation extending back at least four years. Leibniz's new argument is a byproduct of his attempts to satisfy De Volder's repeated requests for a proof of Causal Activity, and appears in the paragraph above only after De Volder, less than three weeks prior, mounts a clear assault on Causal Independence.

In §2.1, I will sketch De Volder's basic philosophical predicament that drives his interest in Leibniz's metaphysics and, in particular, in obtaining a proof of Causal Activity. Then, in §2.2, I will lay out Leibniz's best attempt at an argument for Causal Activity - an argument that hinges on, and draws De Volder's critical attention to, Causal Independence. In §2.3, I will show how De Volder's substance dualism and causal realism - and his misunderstanding of Leibniz's metaphysics of forces-structure the former's attack on, and shape the latter's defense of, Causal Independence. In \$3, I will explain and formulate Leibniz's 
lost argument and the metaphysics on which it is built. In the final section, I will offer a few brief remarks about what we ought to make of this argument.

\subsection{De Volder's Attraction to Leibniz's Metaphysics}

Two important and related questions troubled De Volder. First, what explains the appearance of interaction between minds and bodies? Second, what explains or causes the changes we observe in substances? Given his philosophical commitments, he did not like his options for answering either question. His early education was scholastic, but De Volder later turned to Cartesianism. But despite having a reputation as a Cartesian sympathizer, he was no toady, dissenting from Descartes on, for instance, questions concerning physics and mind-body causal interaction (LDV 141). ${ }^{15}$ While he was committed to the basic Cartesian dualist ontology of two fundamentally different types of substance-extended bodies and thinking minds ( $\operatorname{LDV} 189,93-95,141)^{16}$ - he also believed that there is no way to explain any action of thinking substances on extended substances or vice versa (LDV 141, 93-95, 115, 253). Since De Volder took this mind-body interaction problem to be insoluble, he could not accept interactionism as an answer to the first question above.

Nor did De Volder find occasionalism an acceptable explanation for the apparent interaction of minds and bodies. Although in his correspondence with Leibniz he never outright denied occasionalism, he always resisted it, for at least three reasons. First, he thought the doctrine unworthy of God, since it, in his view, requires God to perform a separate action to cause each creaturely change (LDV 271). Second, he viewed occasionalism's appeal to God as a philosophically dubious move: "a retreat" (LDV 169), and a "summon[ing of] Deus ex machina" (LDV 21). Third, De Volder sought a causal realist account of corporeal substances (bodies) on which the source of bodily motions is found in bodies themselves: "I have never doubted that there is some motive force in body" (LDV 143), he says. But on occasionalism, no created substance can be causally efficacious. So he "never liked the opinion of Malebranche and certain Cartesians that motion arises not from the force of the collision of bodies but from the immediate power of God" (LDV 143). He agreed with Leibniz that our experience confirms that bodies act (LDV 169), so it vexed him that he could not account for intrinsic activity in bodies: "The fact that I have not found the cause of this [activity] in body ... has always bothered me." (LDV 143)

With respect to the second question - what causes changes in substances? - De

15. For a helpful introduction to De Volder's philosophical views vis-a-vis Cartesianism, see Lodge (2005).

16. At LDV 283, De Volder also rejects Spinoza's substance monism precisely because it collapses mind and body into one substance. 
Volder again found occasionalism unacceptable. As noted above, on occasionalism no created substance can be causally active; but De Volder was committed on a posteriori experiential grounds to bodies being just that. However, he also could not see how any body could be intrinsically active. Given his view that the nature of body is purely passive extension, he admitted that bodies without active force are conceivable (LDV 245-247). But then bodies cannot be active by nature, since no substance can be by nature that which we can conceive it not to be. So, at least for corporeal substance, he could not explain Causal Activity. So neither could he rule out occasionalism.

De Volder was attracted to a substance dualist and parallelist approach for answering both of the questions above. On such a view, changes in mind and body would arise from their own respective principles (LDV 63, 141) rather than mind-body causal interaction, thus steering past the mind-body interaction problem without arriving at occasionalism. But De Volder's parallelism stalled out, since, as noted above, he could not see how to fuel bodies with action. Further, he rejected Spinoza's parallelism, since he denied the latter's substance tokenmonism (LDV 283). This left him again with interactionism and occasionalism as the remaining options - the one impossible, he thought, due to the mind-body interaction problem, and the other implausible. But Leibniz's views on substance and pre-established harmony revived De Volder's hopes. He "jumped for joy" (LDV 143) upon reading Leibniz's short 1694 article that promised an account on which substances are active by their very natures (G IV 468/L 432) - precisely the missing key component of De Volder's parallelism. Doubtless Leibniz's promise especially appealed to De Volder, since it was packaged with language apparently consistent with both Cartesian dualism and body-body interaction. If Leibniz could prove that any substance is active by nature, De Volder hoped that this could explain, consistent with his own dualism, what causes change in bodies, all while avoiding both the mind-body problem and occasionalism. But as will become clear in the following section, Leibniz's best attempt to prove Causal Activity-which hinges on defending Causal Independence-left De Volder disappointed.

\subsection{Leibniz's Route to Causal Activity via Causal Independence}

De Volder insisted that "it will be necessary to descend to the notion of substance and to demonstrate that it is necessarily active from its nature" (LDV 61). Without an a priori argument, he thought, we cannot be certain that substances (especially corporeal ones) are active. ${ }^{17}$ But Leibniz never supplied an a priori

17. De Volder makes fourteen requests for such an argument, according to Lodge's tally (1998: 47). 
argument for Causal Activity. Why not? Early in their correspondence, Leibniz admitted that he simply did not have an a priori argument (LDV 47, 157-159, 77-79). But as the correspondence continued, he denied the need for an a priori argument, claiming that Causal Activity can be established a posteriori, by an argument that hinges on Causal Independence-the thesis about which I am most concerned in this paper.

Leibniz first offers this experience-based argument in January of 1700 :

If we grant that one substance cannot influence another, as many concede, it follows from this that any substance whatsoever is intrinsically active. For it is unreasonable to call in God, and it does not explain or change anything. One can even argue that there is no influence of one substance on another from the inexplicability of influence itself. (LDV 157)

More than three years later, in November of 1703 , Leibniz repeats essentially the same argument:

if you agree with me that the system of occasional causes is not worthy of a philosophy, and if you think that the influence of substance on substance (I am speaking about true ones) is inexplicable, I do not see how you could have doubts about the internal tendency to change in things since we are taught that there are changes in things by our experience of the phenomena, as well as from the inside, where the operations of the mind themselves exhibit changes. Therefore, I think the fact is demonstrated a posteriori and your objections are also satisfied. (LDV 279)

Call this the Experience Argument for Causal Activity, which may be reconstructed as follows:

(1) Every substance undergoes change.

(2) Every substance's changes have causes.

(3) The cause of any change in a substance must be either intrinsic to the substance changed, another substance, or God.

(4) Occasionalism is false - that is, the (secondary) cause of any change in a given substance is not God.

(5) Causal Independence is true-that is, the (secondary) cause of any change in a given substance cannot be another substance.

(6) So, the cause of any change in a substance must be intrinsic to that substance itself. [3-5]

(7) So, every substance must be causally active. $[2,6]$ 
De Volder and Leibniz agree that premise (1) is confirmed by experience. ${ }^{18}$ Premise (2) is assumed and follows from the PSR. As Leibniz says early on to De Volder, "each and every thing remains in its state until there is a reason for change. This is a principle of metaphysical necessity" (LDV 73; cf. LDV 213). ${ }^{19}$ Leibniz and De Volder agree that (3) lists the only candidates for causes of substances' changes. De Volder already wants to accept (4) - as discussed above, he sought an alternative to occasionalism from the outset. And after later rehearsing Leibniz's Experience Argument, De Volder grants that "if I assume that the various things in this universe are substances and that they do not act on one another, the rest seems to follow without difficulty" (LDV 271). Premises (1)-(4) leave open that every substance's changes might be caused by other substances; nor do (1)-(4) alone entail that every substance is active, since it might be that some of the substances do all of the work, while some do none. But once we add (5)-viz., Causal Independence-it now follows that every substance must itself cause its own intrinsic changes (i.e., (6)), and thus that every substance is active (i.e., (7)).

What reason does Leibniz give for (5), i.e., Causal Independence? In the January 1700 letter above-wherein he first gives the Experience Argument for Causal Activity - he only briefly suggests a reason: "the inexplicability of influence itself". And when he repeats the Experience Argument later in November 1703, he again cites only this inexplicability claim. Why did he seem to feel no pressure to defend Causal Independence until a few months later, in the January 21, 1704 letter? Upon reading De Volder's April 1700 reply to his first presentation of the Experience Argument, Leibniz concluded that De Volder already accepted Causal Independence. In that reply, De Volder recognizes that Causal Independence - "that one substance cannot influence another" (LDV 169) - is a critical premise in Leibniz's argument for Causal Activity. Apparently unaccustomed to Leibniz's talk of causal interaction in terms of "influence" [influxus], ${ }^{20}$ De Volder offers his best guess at the underlying argument against causal interaction:

I have always been most convinced by what I think you mean by these words, namely, that there is no intelligible passage from the properties of one substance to the properties of another, and so none from the operations of one to the operations of another. (LDV 169)

18. In numerous letters, including his last substantive letter in the correspondence, De Volder agrees that change in substances is confirmed on a posteriori grounds. See LDV 219, 237, 243-245, $271,283-285,317$.

19. Other texts in which Leibniz affirms the PSR include $C_{519} / A_{3}$ 31; C 11/MP 172; G VI 602/ AG 209-210; A VI.iii.587-588.

20. For historical investigation of Leibniz's use of this term, see O'Neill (1993). Cf. Jolley (1998: 594-595). 
One can hardly blame Leibniz for reading this passage and concluding that De Volder indeed accepted Causal Independence. Moreover, De Volder's claim that there can be no "passage from the properties of one substance to the properties of another" appeared to Leibniz as an apt expression of his own implicit argument in the previous letters, as well as in other texts. For instance, Leibniz had elsewhere said that "one cannot explain how something can pass from one thing into the substance of another" (C 521/AG 33), and that one will always run into problems "entertaining something as inconceivable as an accident's passing from one subject to another" (A 6.6.224/NE 224). Although Leibniz does not usually give a clear explanation why substances cannot transfer accidents, in the New Essays he gives a vivid (if parodied) image of accident transfer and a brief indication of the problem: the Scholastics, he thinks, "entertain a picture of little subsistent beings [i.e., accidental forms] which can fly in and out like pigeons with a dovecote. It is unwittingly to turn them into substances" (A 6.6.379/NE 379). The crux of the implied argument is that an accident could be transferred only if it were a substance, which it is not. ${ }^{21}$ In these and other texts, ${ }^{22}$ Leibniz indicates a general argument for Causal Independence that we might call No Accident Transfer:

(1) One substance can cause changes in another only if the first can transfer accidents to the second. ${ }^{23}$

(2) No substance can transfer any accidents to another.

(3) So, no substance can cause changes in another. $[1,2]$

De Volder's April 1700 reply, quoted above, seemed to express just this argument. So Leibniz took it as a settled point of agreement with De Volder that Causal Independence is true, and on the basis of No Accident Transfer, even referring in his next letter, in September 1700, to "the fact that it is proved that [one created substance] can receive nothing from another created substance" (LDV 181; cf. LDV 279).

But this agreement is short-lived or, more likely, simply illusory. For the next two years, other topics (e.g., a suitable notion of substance) dominated Leibniz's and De Volder's letters. In late 1702, however, De Volder begins to resist Causal

21. There may be room to resist this argument. For instance, why think that accidents cannot be transferred instantaneously, so that they would not subsist apart from a substance? So far as I know, Leibniz never discusses this concern. Whether he in fact has the resources to defend this argument, though, is beyond the scope of the present paper.

22. See Footnote 13.

23. For discussion of Scholastics who may have accepted a transfer model of causation, see Wippel (1981: 221-224). Interestingly, some contemporary philosophers accept versions of a transfer model. For instance, Mumford and Anjum (2011: 5-6) accept a 'passing around' model, on which objects cause changes in others by passing powers around between themselves. 
Independence as a general thesis, insisting instead that substances of the same nature -in particular, bodies-can interact. It is this resistance that leads to, and helps to structure, Leibniz's new defense of Causal Independence a handful of letters later.

\subsection{De Volder's Attack on Causal Independence}

Nearly two years after seeming to articulate and accept the No Accident Transfer argument, De Volder begins to put pressure on Causal Independence. Comparing Leibniz's explanation of activity in a harmonized creation with the occasionalists', he says, "Your explanation is better, provided that it may be demonstrated that these substances of yours do not act on one another" (LDV 251), pointing out that Leibniz's defense of Causal Activity turns on Causal Independence. But then De Volder wonders on what grounds Leibniz denies interaction between bodies: "what reason is there for me to deny that these [corporeal] substances act on one another, when I seem to understand their action and the effect of this action so clearly?" (LDV 253)

Two of De Volder's commitments become clear: first, that substances of the same fundamental nature can causally interact, and second, that all bodies are of the same fundamental nature (viz., extension). ${ }^{24}$ On his view, if one substance's changes of modifications can be deduced from the modifications of a second substance, then there is sufficient reason to think that-and no reason to deny that - the second caused the changes in the first. De Volder grants that such a deduction is not possible for two substances of different fundamental natures. This is because modifications are determinations of the substance's fundamental nature (that is, its principal attribute). But for two substances of the same fundamental nature, such a deduction can be had (LDV 253). Thus De Volder claims that the main reason-namely, the mind-body problem-for denying causal interaction between substances does not obtain between corporeal substances:

The other case, when we deny that the mind acts on the body or the body on the mind, is of no help here. As I understand it, we deny it in this case not because they are substances but because they are totally different kinds of substances, so that the properties of one cannot be deduced from the properties of the other, which does not happen in the case of these bodies. (LDV 253, my italics)

24. By "substances of the same fundamental nature" I do not mean to suggest that De Volder is committed to universals of either the immanent or Platonic sort. Rather, the claim is that, e.g., for any two extended substances, each has an individual nature that is exactly similar to the other's, and likewise for any two thinking substances. 
But, De Volder suggests, perhaps Leibniz's entelechies are what prevent interaction between substances. An entelechy, for Leibniz, is the source or principle of activity in a substance-it is both the substance's active force itself and the nature or form according to which its force will manifest (LDV 75-77, 155-157, 263; cf. G VI 149-150; G III 657). ${ }^{25}$ De Volder wonders whether the interaction problem might apply instead to these entelechies governing substances:

You do indeed seem to me to put every entelechy in a different species, or certainly sometimes close to that, though, granted, you do not put it in that way. But I would like to know why you do this, if the explanation of the entelechy is indeed grounded in the nature of these forces. But if things are otherwise and you mean that the entelechy is distinct from these forces, I will ask what it is, and how it might set a mass in motion. For at present this appears just as obscure to me as that which I just said about the mind setting the body in motion. (LDV 253)

Leibniz did, after all, talk as if all entelechies must have different natures (LDV 101, 155-157, 211). Indeed, he confirms De Volder's suspicions, responding that "It is necessary that entelechies differ-i.e., that they not be completely like one another" (LDV 263). De Volder suspects, then, that perhaps Leibniz thinks that these uniquely natured entelechies are what preclude causal interaction between substances. But if that is the case, De Volder presses, then another problem emerges: these entelechies would have natures different from bodies, and thus would seem causally incompatible with the bodies they are supposed to activate. And so, he thinks, this strategy explains Causal Independence but at the same time undermines Causal Activity.

De Volder's suspicion arises partly from a misunderstanding of Leibniz's metaphysics. At this point in the correspondence, De Volder thinks that, on Leibniz's view, a corporeal substance is an ontologically prior mass which God then imbues with a 'derivative force' causing its motions. ('Derivative force' would be inaptly named, were De Volder's understanding of Leibniz's view correct.) God then gives the corporeal substance an entelechy or 'primitive force' which, De Volder suspects, is something very like a Cartesian thinking substance. This entelechy "set[s] a mass in motion" (LDV 253), unifying or directing the derivative force in that substance. So, as De Volder understands Leibniz's view, corporeal substances satisfy Causal Activity precisely because these entelechies activate them.

But in any case, De Volder argues, there is a critical inconsistency here. If

25. Leibniz sometimes uses terms like 'entelechy', 'primitive force', 'substantial form', 'soul', and even 'monad' interchangeably. See G VI 352, G IV 479/AG 139. 
entelechies activate corporeal substances, then, he thinks, entelechies would have to be in some sense grounded in the corporeal substances' forces; otherwise, entelechies must be of a different fundamental nature than corporeal substances. But if that were so, then the mind-body problem would rear its head: non-bodily entelechies could not be the causes of bodily changes. So, if we accept Causal Activity - as a fully general thesis covering all substances, including corporeal ones - then entelechies must be grounded in corporeal substances' forces. But in that case, since corporeal substances are all of the same fundamental nature (viz., extension), all entelechies must be of the same nature as well. If so, we no longer have reason to think that any of these activated corporeal substances are barred from causal interaction, since the bodily masses themselves are all of the same nature, and so, too, are the entelechies grounded in them. Thus, if Causal Activity is true, then Causal Independence must be false: if entelechies activate corporeal substances, then these corporeal substances are able to causally interact.

On the other hand, De Volder argues, if Leibniz insists that no substances can interact, then there must be different fundamental natures lurking somewhere. Since it is clear, De Volder thinks, that corporeal substances are all of the same nature, the different-nature culprits must be the entelechies. As noted above, Leibniz does talk as if entelechies all have different natures. So perhaps something analogous to the mind-body problem bars interaction between entelechies. If these entelechies are each of a different nature, then most cannot be grounded in corporeal forces. And now something like the mind-body problem returns: if entelechies are not all of the same nature as corporeal substances, then the former cannot all causally interact with the latter. But then entelechies cannot activate corporeal substances. So, if Leibniz insists on Causal Independence, it will cost him Causal Activity. Thus, De Volder concludes, Leibniz cannot have both.

Leibniz does not directly address De Volder's argument above. Instead Leibniz tries to clarify his metaphysics of primitive and derivative forces. De Volder had reversed the direction of ontological dependence, thinking that a substance's primitive force is grounded in its derivative forces. But the opposite is true:

derivative forces are nothing but modifications and echoes of primitive forces. . . . corporeal substances cannot be constituted from derivative forces alone joined with resistance, i.e., from vanishing modifications. Every modification presupposed something lasting. (LDV 263)

The primitive force (or entelechy) activates the substance-or rather, just is the substance itself qua active being - and brings about all that happens to the substance. Derivative forces are only modifications of the primitive force. So, no substance's derivative forces can be ontologically prior to its primitive force, since no modification can be prior to that of which it is a modification. Leibniz 
then simply restates Causal Independence with only a quick gesture toward the No Accident Transfer argument: "I do not admit the action of individual substances on one another, since there appears to be no way by which a monad may influence a monad" (LDV 263).

Four months later, in October of 1703, De Volder insists that Leibniz's Experience Argument for Causal Activity makes major assumptions, namely, the metaphysics of monads together with Causal Independence: "if I assume that the various things in this universe are substances and that they do not act on one another, the rest seems to follow without difficulty" (LDV 271, italics added). Leibniz denies that Causal Independence is merely an assumption. Rather, he claims, it is necessary:

you have hit the nail on the head when you judge that, according to my view, what are truly called substances ... have no influence on one another .... However, you seem to depart from my intention because you think that only a hypothesis is being advanced, whereas I think that the doctrine is necessary. (LDV 275)

But he does not yet explain why Causal Independence is necessary, apparently assuming that De Volder ought to recall the No Accident Transfer argument upon which they had seemed to agree three years prior (LDV 181-183). Instead, a frustrated Leibniz repeats the Experience Argument for Causal Activity, and wonders what remains for De Volder to doubt (LDV 279).

Seven weeks later, on January 5, 1704, De Volder mounts his final argument against Causal Independence, which is what prompts Leibniz to give a new defense of this thesis. Adopting a new strategy, De Volder now argues that Leibniz faces a choice: either maintain that his entelechies ground substances' activity, but at the cost of denying that bodies are substances; or allow that bodies are substances, but at the cost of rejecting his entelechies, which in turn undermines Causal Independence. De Volder is antecedently strongly disposed to accept that there are bodily substances and that they can mutually interact. And he already suspects that Leibniz's entelechies trigger a version of the mindbody problem, preventing them from grounding corporeal motions. But now he also cannot see how any substance could, as Leibniz insists, have a cause of its changes that is both intrinsic and follows from its very nature. In De Volder's view, whatever follows from something essential follows permanently, and thus cannot involve changes. He gives an example: whatever follows from the nature of a triangle-e.g., that its angles are equal to two right angles-always follows from it unchangingly (LDV 283). What De Volder has wanted from the beginning is an explanation for how action - the source of change-can come from a substance intrinsically. That is, he wants to explain Causal Activity. The problem 
is, De Volder thinks, that action requires succession, i.e., a change of states in a thing. But then, if a substance is to be intrinsically active, it must be successive in nature. De Volder thinks this shows that derivative forces - i.e., corporeal forces causing motions - are indeed successive. The trouble is that Leibniz insists that true substances are unities, and that a primitive force (entelechy) is what unifies it. But De Volder cannot see how any truly unified thing can be successive in nature:

I do not see how any succession (which is required for action) can follow from the nature of a thing considered intrinsically unless the thing itself is successive, which agrees perfectly with derivative forces but not so much with primitive forces. (LDV 283, my italics)

De Volder seems to think that if a substance's nature is unified and fixed, as Leibniz insists that his primitive forces (entelechies) are, then no substance-cumprimitive force will have changes of modifications following from its nature. So he thinks that Leibniz faces a dilemma:

It is like this: either particular bodies will not be substances, if you demand your unity or primitive force for substances, or if they get called substances they will be substances of the same nature, which nothing prevents from acting on one another. (LDV 283-285)

On the one hand, we can choose to accept that bodies are intrinsically active and thus, he thinks, successive. But then no body can be a true unity endowed with a primitive force, and thus no body can be a substance. This De Volder cannot accept, since he thinks it is obvious that there are corporeal substances. ${ }^{26}$ On the other hand, we can choose to accept that bodies are substances and active by nature. In that case, every corporeal substance's nature must be successive, and thus no substance could be a true unity, and thus could not have one of Leibniz's primitive forces (entelechies). But since entelechies were Leibniz's explanation for substances' having unique natures, dropping the entelechies leaves us with no reason to deny that corporeal substances all have the same fundamental nature (viz., extension). And since, De Volder thinks, substances of the same fundamental nature can indeed interact, corporeal substances sans entelechies can interact. Thus, Causal Independence is false.

De Volder finds the other hand clearly preferable, since his overriding goal

26. De Volder talks in terms of multiple corporeal substances here (LDV 283), though at times (e.g., LDV 115) he appears open (if not committed) to the view that there is but one corporeal substance. Here, though, he distances himself from Spinoza's substance monism, and apparently affirms only a type-monism for corporeal substances. 
was always to find a way to account for active corporeal substances. ${ }^{27}$ It now becomes clear to Leibniz that De Volder denies Causal Independence, and that a key premise in the latter's argument against it is the claim that causal interaction is possible between substances of the same nature.

\section{Leibniz's New Argument for Causal Independence}

Leibniz penned his response just two weeks later. Here again is the paragraph containing his reply to De Volder's argument that Causal Activity's price is to cast aside Causal Independence:

You say, Nothing prevents 'substances of the same nature' from acting on one another. But you know that philosophers have, in fact, denied action between similar things. And what prevents substances of different natures from acting on one another? When you have explained that, you will see that it prevents all finite substances from influencing one another. Not to mention the fact that all substances are of different natures, and that there are no two things in nature that differ in number alone. (LDV 291, italics added $)^{28}$

It is important first to see that this is an argument for Causal Independence, which is clear from the clause highlighted in italics. But how should we understand Leibniz's argument in this paragraph in light of the strands of correspondence leading up to it? Note that he chooses to focus on De Volder's claim that

27. De Volder grants that this solution is not perfect: "I admit that refuge must be taken in God to set up these derivative forces" (LDV 285). But he thinks that Leibniz must admit the same for primitive forces, since De Volder still seems to think that, on Leibniz's view, God imputes primitive force to an ontologically prior mass. This is not Leibniz's view, of course. For Leibniz, a true, simple substance is essentially active (hence, the primitive force), but also essentially limited in a unique way (hence, the primary matter). But these are not separate components that God mashes together to form a substance.

28. It might be tempting to read Leibniz's phrase "Not to mention the fact that [Ut taceam]" as indicating another argument for Causal Independence, one distinct from whatever argument he gives in the sentences prior. Without the broader context of the correspondence, this reading seems prima facie plausible. (Although, even without the broader context, this isn't the only plausible reading.) As will become clear by this section's end, that isn't how I read this passage. Briefly, there are at least two reasons why. First, if Leibniz is giving two distinct arguments in this passage, then the argument before "Ut taceam" is most plausibly the No Accident Transfer argument. But, as I argue below in response to Bennett, that isn't what Leibniz is doing, since by this point in their correspondence he is well aware that De Volder rejects No Accident Transfer. Second, if "Ut taceam" divides two distinct arguments for Causal Independence, and No Accident Transfer comes before the other, then it is hard to see what argument Leibniz could be indicating after that phrase. 
substances of the same nature can interact. He now sees that this is the linchpin of De Volder's resistance to Causal Independence. It is central both to De Volder's argument, in late 1702, that either Causal Activity or Causal Independence must be false; and to his later argument, in early 1704, that corporeal substances can interact.

Leibniz begins by reminding De Volder that "philosophers have, in fact, denied action between similar things", certainly referring to the Cartesian occasionalists, since interactionists accept same-nature interaction. But his appeal to occasionalists here may seem puzzling. For while it is true that occasionalists deny both body-body and mind-mind interaction, they do so for reasons that Leibniz rejects. For instance, occasionalists argue that for any substance to be the true cause of changes - whether in itself or in another substance-it must create the substance-as-changed ex nihilo. But only God possesses this power. ${ }^{29}$ So, their rejection of same-nature interaction follows straightforwardly from their rejection of all causal activity in created substances. Since Leibniz accepts Causal Activity, clearly such arguments are not available to him. For this reason, Louis Loeb judges that Leibniz's invocation of the occasionalists here simply backfires (1981: 295).

But Leibniz is not appealing to the occasionalists for any argumentative support against De Volder. Rather, he now sees that De Volder's case against Causal Independence-and, by extension, against his Experience Argument for Causal Activity-hinges on the claim that same-nature interaction is possible, a claim that De Volder appears to find unassailable, even obvious. Leibniz is pointing out that same-nature interaction is hardly uncontroversial: the occasionalists deny it, as De Volder well knows. His point is that what De Volder thought was safe to assume is in fact centrally at issue. ${ }^{30}$

Once Leibniz has established that affirming same-nature interaction is the key premise in De Volder's argument against Causal Independence, Leibniz's argument proper begins. He asks, "what prevents substances of different natures from acting on one another? When you have explained that, you will see that it prevents all finite substances from influencing one another" (LDV 291). He is claiming that whatever rules out interaction between substances of different fundamental natures also, for the same reason, rules out interaction between all substances. What reason is that?

One tempting way to answer this question is to advert to arguments that

29. For discussion of Malebranche's arguments for Occasionalism, see Nadler (2000).

30. Loeb also suggests that Leibniz's mentioning the occasionalists "amounts to nothing more than an attempt to put De Volder in a frame of mind which might make him more receptive to Leibniz's position" (1981: 295). I agree that Leibniz is pushing De Volder toward a more receptive frame of mind, in the sense that, were De Volder to see that what he assumes is what is at issue, it would make him more receptive to arguments against that assumption. 
Leibniz elsewhere gives against causal interaction. For instance, on Jonathan Bennett's reading of the paragraph above-a paragraph he finds to be "plain enough" (2001: 240), far from "gallingly enigmatic" as Sleigh had thoughtLeibniz "holds that the notion of giving that is at work here-namely, that of the transfer of accidents - is inherently cankered" (2001: 240). For Bennett, then, Leibniz is merely reminding De Volder about the No Accident Transfer argument: no substance can interact with any other, since this would require accident transfer, which is impossible. And it is true, as we have seen, that more than three years prior Leibniz had thought, approvingly, that De Volder had articulated and affirmed that very argument.

But Leibniz is not appealing to No Accident Transfer here. Rather, by asking De Volder to consider why different-nature substances cannot interact, he is directing De Volder's attention to the mind-body interaction problem, which De Volder himself considers insoluble. ${ }^{31}$ But De Volder does not consider it insoluble on the basis of No Accident Transfer. Otherwise, he already would have obvious grounds to deny same-nature interaction. And by now Leibniz is well aware that De Volder insists on same-nature interaction.

While De Volder does not explain how he understands the metaphysics of causation between same-nature substances, presumably either he accepts accident transfer; or he accepts some other metaphysics of causation; or he is agnostic about the matter. If De Volder accepts accident transfer between same-nature substances, then clearly he either came to reject or else never accepted the No Accident Transfer argument. Either way, for Leibniz simply to advance this argument again would be obviously dialectically ineffective-a mistake he is unlikely to have made, having just defended himself one letter ago against the charge of begging the question concerning Causal Activity (LDV 275). If instead De Volder accepts some other metaphysics of causation between same-nature substances, then for Leibniz to reassert the impossibility of accident transfer-a model of causation that, ex hypothesi, De Volder does not accept-would be to tear down a straw man. Or, if instead De Volder is agnostic about the underlying metaphysics, then his commitment to same-nature causation is not predicated on any particular metaphysics of causation. In that case, perhaps it could be effective to advance No Accident Transfer alongside an additional argument

31. See De Volder's comments on the mind-body problem at LDV 141, 93-95, 115, 253. Despite his Cartesianism, he disagrees with Descartes here. Descartes denied the charge that substance dualism rules out mind-body interaction, though he never explained how mind-body interaction could work. He gave two basic replies. First, he seems to have thought that we do observe that minds and bodies interact, and so the burden of proof rests on those who deny mind-body causation (AT III 665). Second, he gave a tu quoque retort, claiming that his scholastic opponents are in the same philosophical boat, since they accept interaction between real accidents and substances, entities of two different ontological categories. See AT III 424-425/CSMK 191; AT IX 213/CSM II 275-276. For discussion, see Radner (1985). 
that accident transfer is the only possible model for inter-substantial causation. But Leibniz does not do this. So, for the above reasons, it is unlikely that Leibniz intended to fall back on the No Accident Transfer argument.

To what argument, then, is Leibniz directing De Volder's attention when he rhetorically asks, "what prevents substances of different natures from acting on one another?" Not any argument that Leibniz himself typically gives. Rather, he is asking De Volder to attend to the mind-body problem that De Volder himself accepts. On De Volder's substance dualism, each substance has one and only one principal attribute which characterizes, and by which we conceive, the essence or nature of the substance. ${ }^{32}$ (On his view, in fact, a substance just is its principal attribute-see LDV 245.) There are two kinds of principal attributes: thought and extension. Every mode of a substance is a determination of, and cannot be conceived apart from, one and only one principal attribute (LDV 187-189). Extended substances (i.e., bodies) have only modes of extension, while thinking substances (i.e., minds) have only modes of thought. So, substances of different principal attributes have no similar modes. In that case, then, no mind-body causal interaction is possible. Hence, De Volder tells Leibniz:

we deny that the mind acts on the body or the body on the mind ... not because they are substances but because they are totally different kinds of substances, so that the properties of one cannot be deduced from the properties of the other (LDV 253, italics added; cf. LDV 93-95, 115, 141)

For De Volder, one substance can act on another only if both substances have modes rooted in the same kind of substance nature. Since no mind has modes of extension, and no body has modes of thought, minds and bodies cannot act on one another. For this sort of reason, early in the correspondence De Volder worried that Leibniz's active principles, or entelechies, would be useless unless they have extension as their nature:

is the active principle extension itself, a mode of extension, or, in fact, some other substance distinct from extension and therefore having nothing in common with it? ... If it is another substance, how can it act on extension? (LDV 93)

If Leibniz's entelechies are not extended, how can they fulfill this ontological commonality requirement? This is, of course, a version of the mind-body interaction problem that Elisabeth, Gassendi, and others raised for Descartes's dual-

32. De Volder follows Descartes here. See CSM I 210/AT VIIIA 25. 
ism. ${ }^{33}$ This problem hinges on what we can call the Same Nature Criterion for causal interaction, an argument for which goes like this: one substance can act on another only if they have compatible modes; and one mode is compatible with another only if each is a mode of a substance of the same fundamental nature; so-and here is the criterion-one substance can act on another only if they have the same fundamental natures. Given this criterion, we can formulate the basic Dualist Interaction Problem as follows:

(1) Same Nature Criterion: Two substances can causally interact only if they have the same fundamental natures.

(2) Minds and bodies do not have the same fundamental natures.

(3) So, no mind and body can causally interact. $[1,2]$

It is precisely to De Volder's Same Nature Criterion that Leibniz appeals in his January 21, 1704 argument for Causal Independence: this criterion is what "prevents all finite substances from influencing one another" (LDV 291). Indeed Leibniz is willing to affirm the general picture of the relationship between modes and principal attributes (i.e., substance natures) which underpins the Same Nature Criterion. For Cartesians, every mode is a determination of, and thus ontologically parasitic on, a principal attribute. Any mode of a body - for instance, a shape -is a determinate way of being extended. Likewise for modes of minds, mutatis mutandis. Leibniz agrees with the general idea, though he sometimes puts the relationship in terms of an absolute thing (the substance's nature) and its limitations or variations (the substance's modifications). In the New Essays, for instance, he explains that modifications

must arise [in a single subject] from limitations or variations of a real genus, i.e. of a constant and absolute inherent nature. For that is how philosophers distinguish the modes of an absolute being from that being itself .... Whenever we find some quality in a subject, we ought to believe that if we understood the nature of both the subject and the quality we would conceive how the quality could arise from it. (A 6.6.65-66/NE $65-66)$

Similarly, he tells De Volder:

modes only limit things and do not increase them, and therefore they cannot contain an absolute perfection that is not in the thing to be modi-

33. See AT III 661; AT VII 339ff/CSM II 235ff; AT VII 420/CSM II 283; AT III 424-425/CSMK 190-191. 
fied. Otherwise, indeed, these accidents would have to be conceived of in the way that substances are, as things depending on themselves. (LDV 277; cf. T \$396/G VI 352)

Every modification is grounded in its substance's nature because the former is but a limitation or variation of - a "way of being" (A 6.6.379/NE 379) - the latter's particular, complete nature.

Now, if this Same Nature Criterion is to rule out interaction between any and all substances, as Leibniz claims, then, contra Cartesian dualism, every substance must have a unique nature, different from every other. But can Leibniz's ontology supply this proliferation of substance natures? In the same letter, he denies substantial status to bodies: "Bodies . . . are nothing but real phenomena, and are no more substances than perihelia or rainbows .... A monad alone is a substance" (LDV 287). Monads, however, are quite mind-like - as he tells De Volder a few months later, the active principle intrinsic to monads "consists in the progress of the perceptions of any monad, and the whole nature of things contains nothing beyond this" (LDV 309; cf. LDV 291, 319, 321; G VI 352; G III 622). So it might seem that Leibniz is a substance nature-monist. But in that case, the Same Nature Criterion cannot fail to be satisfied. For roughly this reason, Loeb argues that no mind-body problem can be formulated on Leibniz's mature metaphysics, since all Leibnizian substances are of the same fundamental nature. ${ }^{34}$ Thus, Loeb suspects, Leibniz's argument in the puzzling paragraph above is probably "[nothing] more than a bluff", and that, in defense of Causal Independence, he "has nothing to offer except a grab bag of responses" (1981: 295, 296).

But Loeb is mistaken. The basic mind-body problem is formulable on Leibniz's metaphysics. In fact, it ramifies to infinity. For Leibniz, the core of the mindbody problem concerns the natures of individual substances. On Cartesian dualism, each individual substance's nature just is its principal attribute. So, every extended substance's nature is the same as every other's, and likewise for thinking substances. Moreover, on De Volder's Cartesian dualism, each substance is identical to its principal attribute (LDV 245). We might say that, on this view, a substance's fundamental type-extension or thought-just is its individual

34. Jorati also appears to see Leibnizian monads as all having the same fundamental natures (2017: 42). Commenting on an exchange in Leibniz's correspondence with Jaquelot (see G VI 563/ WF 190), Jorati suggests that a dualist ontology might furnish Leibniz with the materials for a general argument for Causal Independence, since perhaps it is the immateriality of monads that precludes causal interaction (2017:42). This is an interesting and clever suggestion, though I don't think it succeeds. As I go on to argue, Leibniz thinks that every monad has a different nature, and that this is what precludes interaction, which suggests that sameness of nature would not. Further, Leibniz's more frequently given No Accident Transfer argument is positioned as a general argument applying to any substance, suggesting that monad-monad interaction might not be ruled out purely on the basis of immateriality. 
nature. So, for two substances to have the same substance types just is for them to have the same individual natures.

Leibniz affirms this general picture of substances' natures. In the same letter, he agrees that each substance just is its intrinsic nature: "a certain persisting law, which involves the future states of that which we conceive of as the same, is the very thing that constitutes the same substance" (LDV 291; cf. G IV 518/L 493; G VI 289). He even shows some willingness - with an important qualification - to map Cartesian talk of principal attributes onto his own talk of individual natures. According to Descartes:

To each substance there belongs one principal attribute. . . . A substance may indeed be known through any attribute at all; but each substance has one principal property which constitutes its nature and essence, and to which all its other properties are referred. (AT VIIIA 25/CSM I 210)

Commenting on this passage, Leibniz remarks:

I admit that there is one principal attribute of every substance which expresses its essence, but if we mean an individual substance, I doubt whether this can be explained in words and especially in a few words. (G IV 264/L 390) 35

Leibniz has no quarrel with the ontological role played by principal attributes, namely, being a substance's individual nature in which all of its modes are grounded. What he denies is that the nature of a complete individual substance could be exhausted by a simple attribute (e.g., extension or thought).

But while Leibniz rejects dualism concerning substance types - on his view (at least at this later stage of his career), every substance is a perceiving monad - he also rejects monism concerning substance natures. Immediately after claiming that the Same Nature Criterion - which rules out mind-body interaction on Cartesian dualism - more generally rules out interaction between all substances, he adds that "all substances are of different natures" (LDV 291). Similarly, elsewhere he compares his own view to Aquinas's angels, saying that "the primitive constitution of each spirit [i.e., monad] is different from that of all the others" (G

35. Similarly, in response to De Volder's articulation of Cartesian principal attributes, Leibniz complained: "I do not approve at all of the doctrine of attributes that they formulate these days, as if some one simple absolute predicate (which they call an attribute) constitutes a substance" (LDV 257). But this complaint does not concern a substance's having one fundamental nature, a nature which all of that substance's modifications must presuppose. 
IV 565-566/L 581). ${ }^{36}$ Add to this Leibniz's view that there is an infinity of monads (LDV 291, 303; cf. G IV 492/AG 147), and the result is that, with respect to substance natures, he is neither monist nor dualist, but what we can call a substance infinitist. Thus the metaphysics that Leibniz presents to De Volder does supply another key piece of the mind-body problem as they understand it: substances with different natures. And while Cartesian dualism concerning substance natures drives premise (2) of the Dualist Interaction Problem - no mind and body have the same fundamental natures-Leibniz's substance infinitism substitutes a much more restrictive premise: no two substances have the same fundamental natures.

Now we are in a position to see why Leibniz thinks that the dualist's basic interaction problem also obtains on his own ontology, and in so doing, rules out all inter-substantial causal interaction. We can formulate Leibniz's new Infinitist Argument for Causal Independence as a modified version of the dualists' interaction problem:

(1) Same Nature Criterion: Two substances can causally interact only if they have the same fundamental natures.

(2) No two substances have the same fundamental natures.

(3) So, no two substances can causally interact. $[1,2]$

What makes the Same Nature Criterion so tough to satisfy on Leibniz's metaphysics are the ultra fine-grained individual natures indicated in premise (2). Pick any substance, $\mathrm{s}_{\mathrm{i}}$, from the collection of substances, $\mathrm{s}_{1}, \ldots, \mathrm{s}_{\mathrm{n}}$, and $\mathrm{s}_{\mathrm{i}}{ }^{\prime} \mathrm{s}$ individual nature will be $\mathrm{N}_{\mathrm{i}}$. Then, pick any of $s_{\mathrm{i}}$ 's modifications, and it will be a modification-of- $\mathrm{N}_{i}$, a way of being $\mathrm{N}_{\mathrm{i}}$. Likewise, pick any other substance, $\mathrm{s}_{\mathrm{j}}$, and any one of its modifications will be a modification-of- $N_{j}$. Notice that this is not merely to claim that, for example, $\mathrm{s}_{\mathrm{i}}$ 's modifications are essentially identitydependent on $\mathrm{s}_{\mathrm{i}}$, so that each of these can exist only as a modification of $s_{i}$ in particular. ${ }^{37}$ Even if that latter claim is true on Leibniz's metaphysics, it is not equivalent to, and does not alone follow from, the claim that any of $\mathrm{s}_{\mathrm{i}}$ 's modifica-

36. Cf. G IV 433/AG 41-42; G II 136/LA 170; G VII 316-317/MP 84-85; G IV 518/WF 80; A 6.3.326. In none of those texts, however, is the claim that every substance has a unique nature connected to the rejection of causal interaction between substances. In AG 100 and G VI 289-290/T \$291, the former claim might be read as partly supporting the latter, but not in the way Leibniz is arguing to De Volder in 1704. Rather, the argument would be of the 'no need' variety (see the end of $\S 1$ above).

37. In one text (G IV 364/L 390), Leibniz does appear to accept that modifications are essentially identity-dependent. Some commentators suggest that this is Leibniz's ultimate reason for rejecting inter-substantial causal interaction. See Clatterbaugh (1973: 4, 20), Radner (1985: 47, cf. 45-46), and Lee (2018: 108). However-and curiously-nowhere, so far as I am aware, does Leibniz connect this claim to Causal Independence. 
tions is a modification-of- $N_{i}$, since, for all that, the modification's dependency on $\mathrm{s}_{\mathrm{i}}$ might not involve anything qualitative about $\mathrm{s}_{\mathrm{i}}$ 's nature $\left(\mathrm{N}_{\mathrm{i}}\right)$; the modification's ontological hooks might instead be haecceitistic. Rather, and independently of the question whether or not modifications' dependence are haeccetistic, Leibniz's adoption of the Same Nature Criterion, combined with his metaphysics of ultra-fine grained natures, outfits each substance with its own wardrobe of modifications, each one tailor-made to its substance's unique nature. So, since $\mathrm{N}_{\mathrm{i}}$ is always different than $N_{j}$, no two substances' modifications are compatible, and thus no two substances can meet the Same Nature Criterion for causal interaction. Thus, Causal Independence is true, and it falls right out of the metaphysics that Leibniz presents in the later stages of his correspondence with De Volder.

\section{Concluding Remarks}

De Volder never got what he wanted from Leibniz. In his penultimate letter toward the end of 1704, he was still asking for an a priori demonstration of Causal Activity, though only half-heartedly at that late stage (LDV 317). But in fact De Volder had begun to disengage from the conversation after reading Leibniz's January 21, 1704 letter containing the Infinitist Argument. De Volder had pushed on Causal Independence, and it did not budge. However, this closer inspection revealed Leibniz's reduction of bodies to non-substantial phenomena. Upon seeing this, De Volder began to consider the correspondence a bust, closing his reply to that letter with uncharacteristic frankness: "I would not want to disguise the fact that there were things in your letter that I found completely unacceptable" (LDV 297).

However, De Volder's persistence did move Leibniz to produce a new argument for Causal Independence, namely, the Infinitist Argument. What are we to make of this argument? I shall offer a few brief comments in closing. First, it is a new Leibnizian argument for Causal Independence. When Leibniz gives reasons for Causal Independence in prior works, he never deploys any version of the Infinitist Argument; rather, he either indicates some version of No Accident Transfer or argues that inter-substantial interaction is unnecessary for explaining the appearance of order in nature. ${ }^{8}$ This is so even in works in which-like his correspondence with De Volder-Leibniz has a broadly Cartesian (and thus substance dualist) audience in mind. For instance, when he publicly unveils his pre-established harmony in the New System of Nature in 1695, the only clear reason he gives for Causal Independence is along the lines of No Accident Transfer,

38. For brief discussions of these arguments, see the end of $\S 1$, Footnote 12, Footnote 13, and $\S 2.2$. 
when he claims that the "transmission of species or qualities, as the common philosophers [i.e., Scholastics] imagine" is impossible (G IV 484/AG 143-144). He repeats this reason in his subsequent clarifications to Foucher (G IV 495/WF 49), De Beauval (G IV 497-499/AG 147-148; G IV 501), and Bayle (G IV 520/WF 82). Similarly, in the New Essays in 1702, when discussing inter-substantial interaction in the context of substance dualism, Leibniz claims that, in general, "an accident's passing from one subject to another" is "inconceivable" (A 6.6.224/NE 224). In none of these texts does Leibniz use the claim that every substance has a unique nature as a premise in an argument for Causal Independence.

Moreover, the development of the Infinitist Argument in the De Volder correspondence itself suggests that Leibniz had not previously had this argument in mind. Early in the correspondence, in December of 1698, Leibniz responds to De Volder's interest in the pre-established harmony as an alternative to occasionalism (LDV 21) by directing him to the recently published New System and subsequent clarifications (LDV 47). If Leibniz had already had the Infinitist Argument in mind when writing the New System, it seems likely that he would have mentioned this argument early in the De Volder correspondence. Instead, the first argument for Causal Independence that Leibniz gives to De Volder, in January of 1700 , is No Accident Transfer (see \$2.2). It is only after De Volder's sustained pressure on Causal Independence, from late 1702 until January of 1704, that Leibniz formulates the Infinitist Argument in its defense. This suggests that, prior to this period, Leibniz did not have this argument in mind.

Second, the Infinitist Argument is, in a way, a more conservative argument. Since Leibniz builds it atop his distinctive ontology, advancing the argument is defensive in nature: if we accept Leibniz's infinity of substances with ultra finegrained natures and the relation between substances' natures and modes, then we can see why no substances can causally interact. By contrast, the No Accident Transfer argument appears to assume only a generic ontology of substances and accidents, which permits more room for Leibniz's opponents to resist. (Why think accident transfer is the only way for substances to interact? And why think that accident transfer is impossible?)

Finally, the Infinitist Argument may be more robust than No Accident Transfer. The latter argument presupposes that accident transfer is the only model for inter-substantial causal interaction. But the Infinitist Argument, strictly speaking, need not presuppose this. According to this argument, no two substances have the same nature, and because of this, no substance's accidents can be compatible with any other substance's accidents. This seems to rule out, as a class, any model of causal interaction requiring compatibility of accidents between agent and patient substances. This class certainly includes the transfer model, but it might include others as well. For instance, it might rule out any Scholastic model-and Leibniz is certainly keen to reject Scholastic models of causation (G 
IV 148/L 126; G IV 554/L 574; G IV 499/AG 148)-on which an agent's accident actualizes a patient's potency, but where that actualized potency must be in some sense compatible with the agent's accident. Thus the Infinitist Argument might well add stability to Causal Independence, in turn helping to support Causal Activity and, in so doing, propping up pre-established harmony.

\section{Acknowledgments}

I would like to thank Brian Cutter, Jeffrey K. McDonough, Samuel Newlands, Philip-Neri Reese, Raphael Mary Salzillo, Christopher Shields, and an anonymous referee for helpful discussions of the material in this paper. I am also grateful to audience members at the Early Modern-Saint Louis conference, as well as at Notre Dame and Indiana University-South Bend, for their insightful questions and suggestions.

\section{References}

Adams, Robert M. (1994). Leibniz: Determinist, Theist, Idealist. Oxford University Press. Aquinas, Thomas (1956). [SCG] Summa Contra Gentiles: Book Three: Providence Part I (Vernon J. Bourke, Trans.). Doubleday.

Bennett, Jonathan (2001). Learning from Six Philosophers: Descartes, Spinoza, Leibniz, Locke, Berkeley, Hume, Volume 1. Clarendon Press.

Carlin, Laurence (2006). Leibniz on Final Causes. Journal of the History of Philosophy, 44(2), 217-233. https://doi.org/10.1353/hph.2006.0022

Clatterbaugh, Kenneth C. (1973). Leibniz's Doctrine of Individual Accidents. Steiner.

Clatterbaugh, Kenneth C. (1999). The Causation Debate in Modern Philosophy, 1637-1739. Routledge.

Freddoso, Alfred J. (1994). God's General Concurrence with Secondary Causes: Pitfalls and Prospects. American Catholic Philosophical Quarterly, 67(2), 131-156. https://doi. org/10.5840/acpq199468224

Jolley, Nicholas (1998). Causality and Creation in Leibniz. The Monist, 81, 591-611. https:// doi.org/10.5840/monist199881430

Jorati, Julia (2015). Leibniz on Causation - Part 1. Philosophy Compass, 10(6), 389-397. https://doi.org/10.1111/phc3.12237

Jorati, Julia (2016). Divine Faculties and the Puzzle of Incompossibility. In Yual Chiek and Gregory Brown (Eds.), Leibniz on Compossibility and Possible Worlds (175-199). Springer. https://doi.org/10.1007/978-3-319-42695-2_8

Jorati, Julia (2017). Leibniz on Causation and Agency. Cambridge University Press. https:// doi.org/10.1017/9781108131629

Lee, Sukjae (2004). Leibniz on Divine Concurrence. Philosophical Review, 113(2), 203-248. https://doi.org/10.1215/00318108-113-2-203

Lee, Sukjae (2018). Causation. In Dan Kaufman (Ed.), The Routledge Companion to Seven- 
teenth Century Philosophy (87-116). Routledge. https://doi.org/10.4324/97813157719604

Leibniz, G. W. (1903). [C] Opuscules et fragments inédits de Leibniz. Louis Couturat (Ed.). Presses Univerisitaires de France.

Leibniz, G. W. (1967). [LA] The Leibniz-Arnauld Correspondence. H. T. Mason (Ed. and Trans.). Manchester University Press.

Leibniz, G. W. (1973). [MP] Philosophical Writings. Mary Morris and G. H. R. Parkinson (Eds.). Dent.

Leibniz, G. W. (1976). [L] Philosophical Papers and Letters. Leroy E. Loemker (Ed.). D. Reidel. https://doi.org/10.1007/978-94-010-1426-7

Leibniz, G. W. (1989). [AG] Leibniz: Philosophical Essays. Roger Ariew and Daniel Garber (Eds.). Hackett.

Leibniz, G. W. (1996). [NE] New Essays on Human Understanding. Peter Remnant and Jonathan Bennett (Eds.). Cambridge University Press. https://doi.org/10.1017/ CBO9781139166874

Leibniz, G. W. (1997). [WF] Leibniz's 'New System' and Associated Contemporary Texts. R. S. Woolhouse and Richard Francks (Eds.). Oxford University Press. https://doi. org/10.1093/actrade/9780198248460.book.1

Leibniz, G. W., and Burchard de Volder (2013). [LDV] The Leibniz-de Volder Correspondence: With Selections from the Correspondence Between Leibniz and Johann Bernoulli (Paul Lodge, Trans.). Yale University Press.

Lodge, Paul (1998). The Failure of Leibniz's Correspondence with De Volder. The Leibniz Review, 8, 47-67. https://doi.org/10.5840/leibniz199881

Lodge, Paul (2005). Burchard de Volder: Crypto-Spinozist or Disenchanted Cartesian? In Tad Schmaltz (Ed.), Receptions of Descartes: Cartesianism and Anti-Cartesianism in Early Modern Europe (117-133). Routledge.

Loeb, Louis (1981). From Descartes to Hume: Continental Metaphysics and the Development of Modern Philosophy. Cornell University Press.

Mates, Benson (1986). The Philosophy of Leibniz: Metaphysics and Language. Oxford University Press.

McDonough, Jeffrey K. (2007). Leibniz: Creation and Conservation and Concurrence. The Leibniz Review, 17, 31-6o. https://doi.org/10.5840/leibniz2007172

McDonough, Jeffrey K. (2008). Leibniz's Two Realms Revisited. Nô̂s, 42(4), 673-696. https://doi.org/10.1111/j.1468-0068.2008.00696.x

Mumford, Stephen and Rani Lill Anjum (2011). Getting Causes from Powers. Oxford University Press. https://doi.org/10.1093/acprof:oso/9780199695614.001.0001

Nadler, Steven (200o). Malebranche on Causation. In Steven Nadler (Ed.), The Cambridge Companion to Malebranche (112-138). Cambridge University Press. https://doi. org/10.1017/CCOL0521622123.006

O'Neill, Eileen (1993). Influxus Physicus. In Steven Nadler (Ed.), Causation in Early Modern Philosophy (27-56). Pennsylvania State University Press.

Radner, Daisie (1985). Is There a Problem of Cartesian Interaction? Journal of the History of Philosophy, 23(1), 35-49. https://doi.org/10.1353/hph.1985.0012

Sleigh, R. C. (1990). Leibniz \& Arnauld: A Commentary on Their Correspondence. Yale University Press. https://doi.org/10.2307/j.ctt211qwf3

Sleigh, R. C. (2009). Moral Necessity in Leibniz's Account of Human Freedom. In Samuel Newlands and Larry M. Jorgensen (Eds.), Metaphysics and the Good: Themes from the 
Philosophy of Robert Merrihew Adams (252-271). Oxford University Press. https://doi. org/10.1093/acprof:oso/9780199542680.003.0007

Wippel, John F. (1981). The Metaphysical Thought of Godfrey of Fontaines: A Study in Late Thirteenth Century Philosophy. CUA Press.

Woolhouse, R. S. (1982). The Nature of an Individual Substances. In Michael Hooker (Ed.), Leibniz: Critical and Interpretive Essays (45-64). Manchester University Press. 